\title{
BOOKS
}

\section{NEW TEXTBOOK IN GASTROENTEROLOGY} Gastroenterology - Clinical Science and Practice, vols 1 and 2, 2nd edn, edited by IAD Bouchier, RN Allan, HJF Hodgson, MRB Keighley (1993). WB Saunders Company Ltd, 55 Horner Avenue, Toronto, Ontario M8Z 4X6. 955 pages; \$256.00.

I welcomed the opportunity to review this textbook as it came at a time when I was considering new gastroenterology textbooks to replace my current ageing and outdating ones. This textbook comes as a two-volume, hardcover text. The first volume contains four sections: mouth/pharynx/esophagus, stomach/duodenum, small intestine and colon/rectum/anus. The second volume contains nine sections: gastrointestinal bleeding/ischemia, acute abdomen, inflammatory bowel disease, systemic disease/skin, infections, functional disorders, pancreas, gallbladder/bile ducts and peritoneum. There are over 1800 pages of text; contributions are mainly from British and American authors, with the sole Canadian being Dr $\mathrm{G}$ Forstner on cystic fibrosis.

The purpose of this text is to synthesize theory with practice, attempting to integrate disease concepts with clinical, diagnostic and therapeutic approaches. Superficially, the textbook appears quite comprehensive and seems to provide a good resource for both common and uncommon gastrointestinal problems that the clinician may encounter. The editors should be congratulated for devoting an entire chapter to inflammatory bowel disease and one on functional disorders of the gut, and for often including the clinical approach to many of the presenting gastrointestinal problems. However, the main criticism with this textbook is that many of the sections lack sufficient detail to provide more than a brief overview of these clinical problems, leading to the frustration of having to use additional references. As well, a number of topics - such as Helicobacter pylori and acquired immunodeficiency syndrome, and the gut - are not discussed as a distinct entity, rather the discussion is often scattered. I see this textbook as valuable to undergraduates and to family medicine/internal medicine residents as well as to general internists but deem it too superficial as the standard text for the practising gastroenterologist.

Lawrence J Worobetz MD FRCPC Division of Gastroenterology Department of Medicine University of Saskatchewan Saskatoon, Saskatchewan 


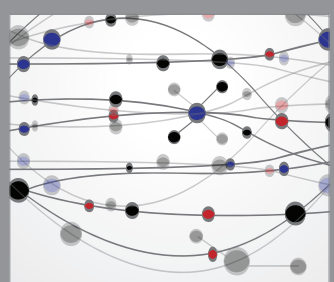

The Scientific World Journal
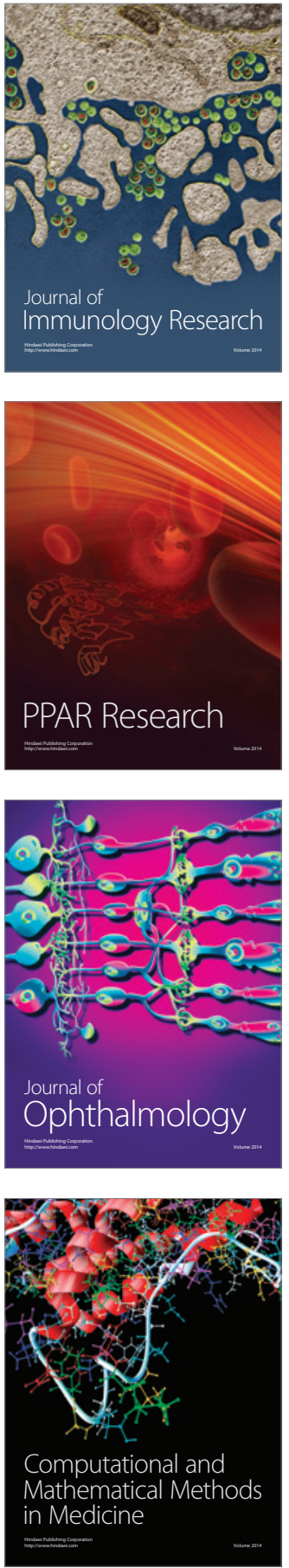

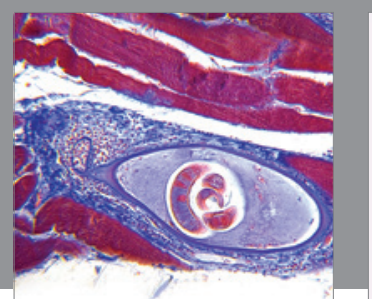

Gastroenterology Research and Practice

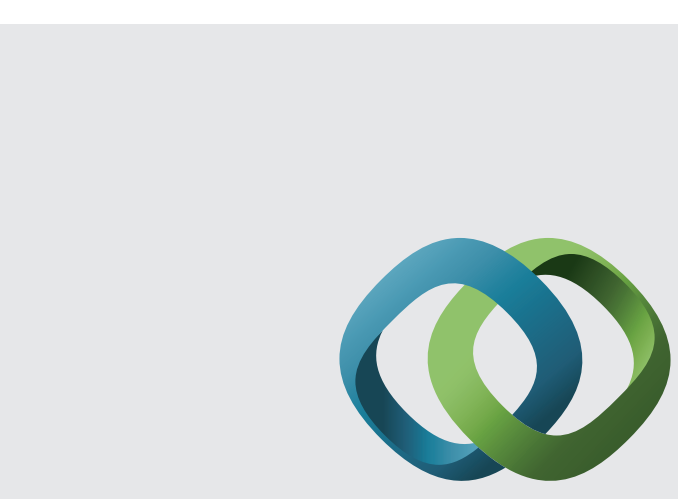

\section{Hindawi}

Submit your manuscripts at

http://www.hindawi.com
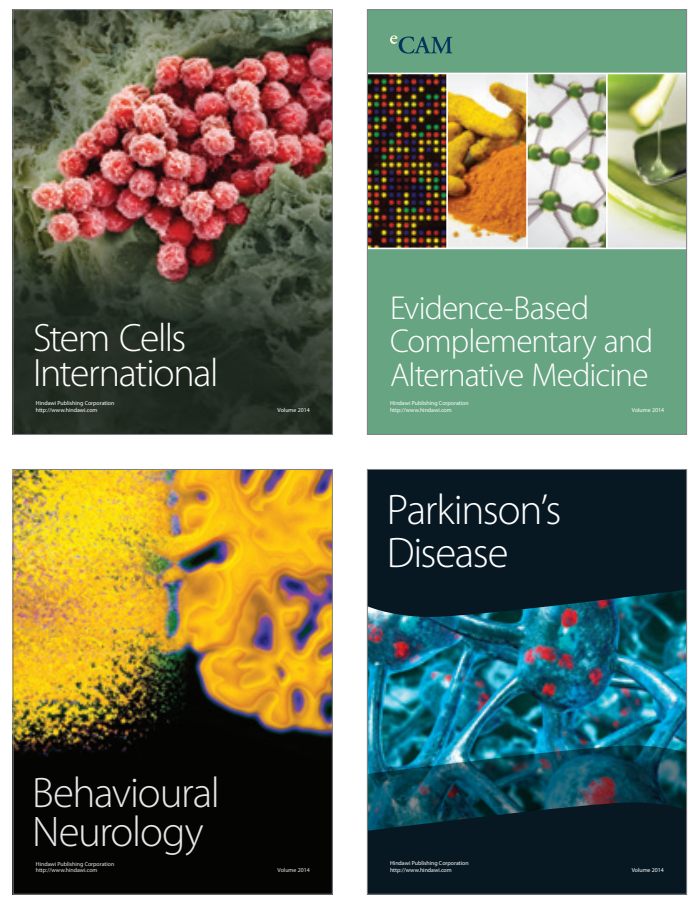


Disease Markers
